\title{
KUALITAS MUTU SAYUR KASEPAK (KANGKUNG, SELADA, DAN PAKCOY) DENGAN SISTEM BUDIDAYA AKUAPONIK DAN HIDROPONIK
}

Quality of Kasepak Vegetables (Water Spinach, Lettuce and Bok Choi) using Aquaponic and Hydroponic System

\author{
Laela Endah Rahmadhani ${ }^{1)}$, Laily Ilman Widuri ${ }^{2)}$, Parawita Dewanti ${ }^{2) *}$ \\ ${ }^{1)}$ Jurusan Agroteknologi, Fakultas Pertanian, Universitas Jember \\ ${ }^{2)}$ Jurusan Agronomi, Fakultas Pertanian, Universitas Jember \\ Jalan Kalimantan No. 37 Jember, 68121 \\ *Korespondensi Penulis: parawita@yahoo.co.id
}

\begin{abstract}
Aquaponic is considered one of alternative culture system to improve production and quality of leafy vegetables by combining soil less culture and fish farming. Utilization of fish manure contained in waste water provides nutrient sources for growing plants. Three kinds of leafy vegetables including water spinach (Ipomoea aquatica F.), green coral lettuce (Lactuca sativa L.), and bok choi (Brassica rapa L.) were grown using both aquaponic and hydroponic system at the Green House in Serut village, Panti District, Jember Regency, from April to June 2019. Productions of each leafy vegetable were evaluated on both culture systems. Water spinach represented $29.12 \%$ higher production in aquaponic than hydroponic system, shown by significant value in plant height, number of leaves, root volume, and leaf fresh weight. Otherwise, bok choi production displayed $17.03 \%$ increased in hydroponic than aquaponic system. However, leaf production of lettuce was not significant between hydroponic and aquaponic system. Lettuce production in aquaponic only $1.90 \%$ lowest than hydroponic system indicated that lettuce was appropriate to cultivate in both farming systems.
\end{abstract}

Keywords: aquaculture, Brassica rapa L., leaf fresh weight, Ipomoea aquatica $F$., Lactuca sativa L., soil less culture

\section{PENDAHULUAN}

Akuaponik merupakan perpaduan antara akuakultur (budidaya ikan) dan budidaya tanaman secara hidroponik dalam satu tempat. Prinsip dasar akuaponik adalah dapat dilakukan pada waktu yang bersamaan dengan cara memanfaatkan limbah kotoran ikan dan sisa makanan ikan sebagai sumber nutrisi bagi tanaman yang dibudidayakan (Nugroho et al., 2012).

Ikan lele (Clarias gariepinus) merupakan salah satu jenis ikan air tawar yang banyak dibudidaya oleh masyarakat karena mudah pemeliharaannya serta memiliki nilai jual yang tinggi. Hal ini dapat dilihat dari peningkatan produksi ikan lele. Berdasarkan data Kementerian Kelautan dan Perikanan (KKP, 2018) bahwa pada tahun 2009-2014 produksi ikan lele mengalami peningkatan sebesar $45 \%$ dari produksi awal 200.000 ton menjadi 900.000 ton. Peningkatan produksi tersebut tentunya diiringi dengan peningkatan limbah yang dihasilkan. Budidaya ikan lele menghasilkan limbah dalam bentuk padatan/endapan dan cair bersumber dari kotoran serta sisa pakan ikan.

Limbah ikan lele ini dapat menurunkan kondisi perairan dan memberikan pengaruh buruk terhadap tingkah laku, proses fisiologis, pertumbuhan, serta mortalitas ikan. Air limbah ikan lele yang mengandung bahan organik tersebut akan dimanfaatkan tanaman sebagai sumber nutrisi untuk pertumbuhannya. Prinsip ini menggunakan resirkulasi yaitu penggunaan kembali air yang telah dikeluarkan. Keuntungan dari sistem ini dapat mengurangi kebutuhan air, reduksi bahan organik yang meliputi 
amonia, nitrit serta penyangga atau buffer pH (Effendi et al., 2015).

Tingginya mortalitas ikan yang dipelihara dengan sistem resirkulasi dapat mengganggu kelangsungan hidup ikan. Faktor yang menyebabkan tingginya mortalitas ikan adalah kualitas air. Amonia dalam kondisi anaerob bersifat toksik dan mengganggu kelangsungan hidup. Sistem akuaponik dapat mempertahankan kualitas air, merombak ammonia menjadi senyawa yang tidak berbahaya bagi kehidupan dan pertumbuhan ikan. Amonia dioksidasi menjadi nitrit oleh bakteri Nitrosomonas yang kemudian dalam kondisi aerob nitrit dioksidasi menjadi nitrat oleh bakteri Nitrobacter (Saptarini, 2010). Berikut data kandungan unsur hara makro yang terkandung dalam limbah ikan lele (Tabel 1).

Tabel 1. Kandungan kadar hara makro air limbah budidaya lele

\begin{tabular}{lccc}
\hline Variabel & Satuan & Kisaran & $\begin{array}{c}\text { Rata- } \\
\text { rata }\end{array}$ \\
\hline A. Limbah Cair & & & \\
\hline $\mathrm{pH}$ & Unit & $7-8$ & $7-8$ \\
C-organik & $\%$ & $0,28-0,98$ & 0,63 \\
Nitrogen total $(\mathrm{N})$ & $\%$ & $0,98-1,67$ & 1,32 \\
Phosfor total $\left(\mathrm{P}_{2} \mathrm{O}_{5}\right)$ & $\%$ & $1,89-3,40$ & 2,64 \\
Kalium total $\left(\mathrm{K}_{2} \mathrm{O}_{5}\right)$ & $\%$ & $1,10-1,03$ & 0,35 \\
\hline B. Limbah Padat & & & \\
\hline pH & Unit & $7-8$ & $7-8$ \\
C-organik & $\%$ & $16,28-24,64$ & 21,67 \\
C/N ratio & $\%$ & $1,71-12,38$ & 6,71 \\
Nitrogen total $\left(\mathrm{N}^{2}\right)$ & $\%$ & $1,9913,97$ & 6,23 \\
Phosfor total $\left(\mathrm{P}_{2} \mathrm{O}_{5}\right)$ & $\%$ & $4,10-4,69$ & 4,46 \\
Kalium total $\left(\mathrm{K}_{2} \mathrm{O}_{5}\right)$ & $\%$ & $2,31-4,09$ & 3,21 \\
\hline
\end{tabular}

Sumber: Andriyeni et al. (2017)

Menurut Setijaningsih dan Umar (2015), keuntungan budidaya akuaponik adalah memanfaatkan komponen hidroponik sebagai biofilter. Menurut Petrea et al. (2014), budidaya dengan sistem akuaponik dapat memperoleh produk hasil tanaman yang berkualitas. Putra et al. (2013) menambahkan bahwa hasil produksi tanaman sawi dapat meningkat antara 250,8-1.161 g. Rokhmah et al. (2014) menyatakan bahwa dengan sistem akuaponik, penyerapan unsur hara hasil limbah ikan lebih efektif, sehingga meningkatkan produksi tanaman.

Penelitian ini menggunakan tiga jenis tanaman sayuran daun yaitu kangkung, selada dan pakcoy. Kangkung merupakan tanaman yang dapat berfungsi sebagai sebagai fitoremediator (Effendi et al. 2015; Lestari, 2013; dan Indah et al. 2014) sedangkan pakcoy disinyalir sebagai tanaman yang dapat menyerap bahan organik (Andreeilee et al. 2014). Oleh karena manfaat dari kangkung (Ipomoea aquatica F.), selada (Lactuca sativa L.) dan pakcoy (Brassica rapa L.) tersebut, tujuan penelitian ini adalah untuk mengetahui produksi 3 jenis sayuran daun pada sistem budidaya akuaponik dengan kombinasi ikan lele spesies mutiara (Clarias gariepinus) dan sistem budidaya hidroponik.

\section{METODE PENELITIAN}

\section{Alat dan Bahan}

Alat yang digunakan terdiri instalasi hidroponik dengan 216 lubang tanam, kolam ikan berukuran $2 \times 3 \mathrm{~m}^{2}$ dan kolam dekomposisi limbah kotoran ikan berukuran $1 \mathrm{~m}^{2}$, pompa air (Halico), TDS dan EC meter digital (Spek digiticez.dw3), OEM pH meter hidroponik digital, thermometer dan higrometer analog raksa DYWSJ, Chlorophylmeter SPAD 502 Konica Minolta, dan timbangan digital SF 400.

Bahan yang digunakan yaitu bibit tanaman kangkung (Ipomoea aquatica F.), selada (Lactuca sativa L.) dan pakcoy (Brassica rapa L.), ikan lele umur 1 bulan dengan ukuran $7 \mathrm{~mm}$ (diameter kepala), pakan ikan lele spesies mutiara (Clarias gariepinus), rockwool, nutrisi $\mathrm{AB}$ mix (goodplant), dan EM4 pupuk cair pertanian dan dan EM4 pupuk cair peternakan (SLP). 


\section{Tahapan Penelitian}

Pembibitan Tanaman

Benih selada, pakcoy dan kangkung disemaikan selama 10 hari pada media tanam rockwool. Pindah tanam dilakukan saat bibit berdaun 3-4 helai.

\section{Persiapan Kolam, Instalasi, dan Tebar Ikan}

Perangkat akuaponik disiapkan agar sesuai dengan perlakuan. Penebaran ikan lele sebanyak 1.200 ekor ditebarkan ke kolam yang telah siap digunakan dan terisi air dengan volume $6 \mathrm{~m}^{3}$ (Gambar 1).

\section{Persiapan Nutrisi}

Setelah ikan ditebar 7 hari, dilakukan proses dekomposisi limbah kotoran ikan lele yang telah diberi tambahan EM4 sebanyak $10 \mathrm{cc} /$ liter pada volume air $1 \mathrm{~m}^{3}$. Selain itu juga pembuatan nutrisi AB Mix untuk sayuran. Konsentrasi AB Mix untuk tanaman sayuran diatur sebagai berikut: minggu ke-1 900 ppm, minggu ke-2 1000 ppm, minggu ke-3 1100 ppm, dan minggu ke-4 1200 ppm.

\section{Penanaman dan Pemeliharaan}

Penanaman dilakukan dengan memindah bibit ketiga jenis sayuran ke talang hidroponik sesuai denah percobaan. Pemeliharaan meliputi pemeliharaan akuaponik ikan dan tanaman dan hidroponik. Ikan diberikan pakan sebanyak 3 kali sehari sedangkan tanaman diberikan nutrisi dari limbah kotoran ikan dan untuk hidroponik diberi nutrisi $\mathrm{AB}$ mix. Manajemen pemberian pakan pada ikan lele didasarkan pada berat total ikan, dimana secara acak ikan ditimbang beratnya setiap minggu untuk menentukan takaran pakan yang diberikan. Pengambilan sampel dilakukan pada ikan sebanyak 10 ikan. Adapun rumus pakan ikan yang akan digunakan yaitu: berat total ikan x 5\%. Pemberian nutrisi pada tanaman akuaponik diberikan dengan cara tersirkulasi dengan menggunakan mesin pompa air. Mesin dinyalakan selama 9 jam mulai dari jam 07.00-16.00.

\section{Panen dan Pengamatan}

Panen dilakukan pada tanaman berumur 25-45 hari. Kriteria panen untuk selada yaitu berumur 30-44 hari. Selada yang siap dipanen daun bawahnya hampir menyentuh tanah, daun dewasa berwarna hijau cerah dan daun melebar bergelombang (Syariefa et al., 2014). Untuk pakcoy dan kangkung siap panen pada umur 25-30 hari setelah pindah tanam. Ciri pakcoy siap panen yaitu daun berbentuk oval melebar menyerupai sendok yang mengarah ke bawah. Ciri kangkung siap dipanen yaitu daun berwarna hijau tua dan terbuka melebar bentuk daun segitiga (Tintondp, 2015).

\section{Rancangan Percobaan}

Penelitian ini menggunakan rancangan acak lengkap (RAL) faktor tunggal dengan 9 ulangan. Petak percoban akuaponik terdiri atas 2 bagian yakni rangkaian sistem akuaponik dan hidroponik. Unit percobaan sebanyak 27 dimana masing-masing unit terdiri dari 6 tanaman. Sebagai pembanding, dibuat perlakuan kontrol dengan sumber nutrisi larutan $\mathrm{AB}$ mix, sehingga secara keseluruhan pada percobaan terdiri dari 216 tanaman dengan 3 jenis sayuran daun S1 (kangkung), S2 (selada) dan S3 (pakcoy).

Data yang diperoleh kemudian dianalisis menggunakan analisis SEM (standart error minimum). Analisis ini digunakan untuk menunjukkan perbedaan di antara perlakuan satu dengan lainnya yang ditampilkan dalam bentuk bar dengan perolehan nilai rata-rata. 


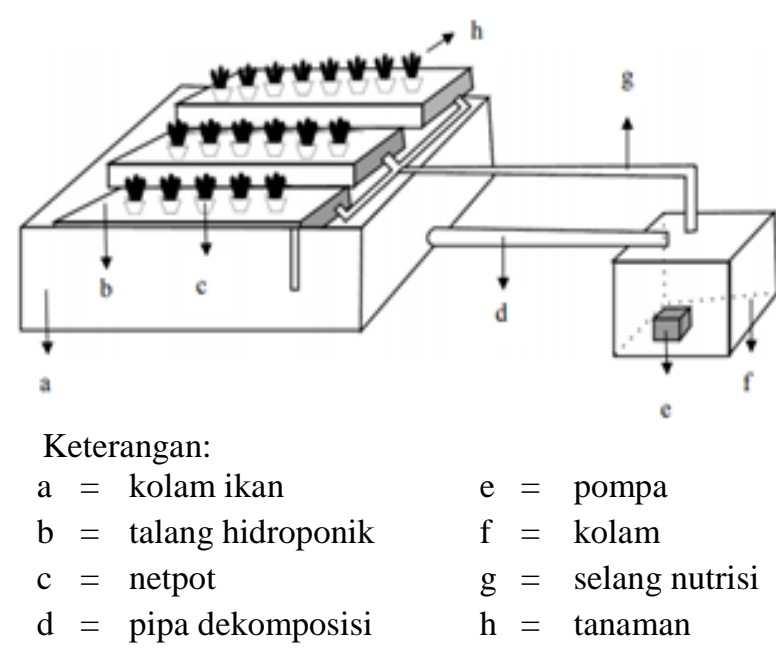

Gambar 1. Bagan rancangan bangun akuaponik

\section{Metode Analisis}

Analisis yang dilakukan adalah pengukuran tinggi tanaman dan lebar daun dilakukan secara kuantitatif menggunakan penggaris. Tinggi tanaman dihitung mulai dari titik pangkal batang sampai ujung daun tertinggi dari tanaman sedangkan pengukuran lebar daun dilakukan dengan menarik jarak antara garis daun terluar dari kedua sisi daun (Oktabriana, 2017; Widuri et al., 2017).

Pengukuran jumlah daun dilakukan pada daun yang sudah membuka penuh sebagai sampel dan untuk berat daun diukur dengan alat ukur timbangan digital setelah panen. Analisis volume akar tanaman dilakukan dengan cara mencelupkan akar tanaman pada gelas ukur berisi air. Perhitungan volume akar di dapat dari selisih kenaikan volume akar sesuai yang tertera ada gelas ukur.

Klorofil diukur ketika panen menggunakan alat Chlorophylmeter SPAD 502 yang dilakukan dengan cara menjepitkan SPAD pada daun tanaman. Sampel daun pada satu tanaman diambil sebanyak 3 helai daun, yakni daun bawah, tengah, dan atas. Adapun nilai Indeks klorofil daun (X) digunakan untuk mengetahui nilai klorofil a $\mu \mathrm{mol} / \mathrm{m})$, klorofil b $(\mu \mathrm{mol} / \mathrm{m})$, total klorofil $(\mu \mathrm{mol} / \mathrm{m})$ dan kandungan $\mathrm{N}$ total daun $(\mathrm{g} /)$. Berikut persamaan nilai klorofil menurut Netto at al. (2005):

$\mathrm{Ka}=(15,5866+1,0338 \mathrm{X}+0,0679 \mathrm{X} 2)$

$\mathrm{Kb}=(30,14710,4592 \mathrm{X}+0,0270 \mathrm{X} 2)$

$\mathrm{KT}=(44,5885+0,7188 \mathrm{X}+0,0933 \mathrm{X} 2)$

Dimana $\mathrm{Ka}$ merupakan klorofil atas, $\mathrm{Kb}$ klorofil bawah, Kt klorofil tengah.

Kandungan nitrogen dalam tanaman dapat diperoleh melalui hasil pengukuran klorofil menggunakan alat ukut SPAD yang mana kemudian dihitung menggunakan persamaan rumus menurut (Netto at al., 2005).

$$
\mathrm{N}=(0,6716+0,0194 \mathrm{X}) \text {. }
$$

\section{HASIL DAN PEMBAHASAN}

Pertumbuhan kangkung dengan menggunakan sistem akuaponik, menunjukkan hasil terbaik dibanding dengan kangkung sistem hidroponik. Namun pada tanaman selada menunjukkan hasil yang tidak berbeda nyata antara selada akuaponik dan hidroponik, sedangkan pakcoy hidroponik menunjukkan pertumbuhan yang lebih baik dibandingkan hasil akuaponik.

Pada awal budidaya ikan dimungkinkan kotoran ikan dan sisa pakan masih belum terdekomposisi dengan sempurna, sehingga akan mengganggu pertumbuhan tanaman. Namun dari hasil penelitian menunjukkan bahwa tanaman kangkung akuaponik lebih baik dibandingkan tanaman kangkung hidroponik karena kangkung sebagai fitoremediator yang diduga mampu menyerap amonia dari limbah kotoran ikan lele. Berbeda dengan tanaman selada dan pakcoy hidroponik pertumbuhannya lebih baik dibandingkan selada dan pakcoy akuaponik. Gambar 2 menunjukkan perbandingan hasil budidaya akuaponik dengan hidroponik pada ketiga jenis sayuran daun. 


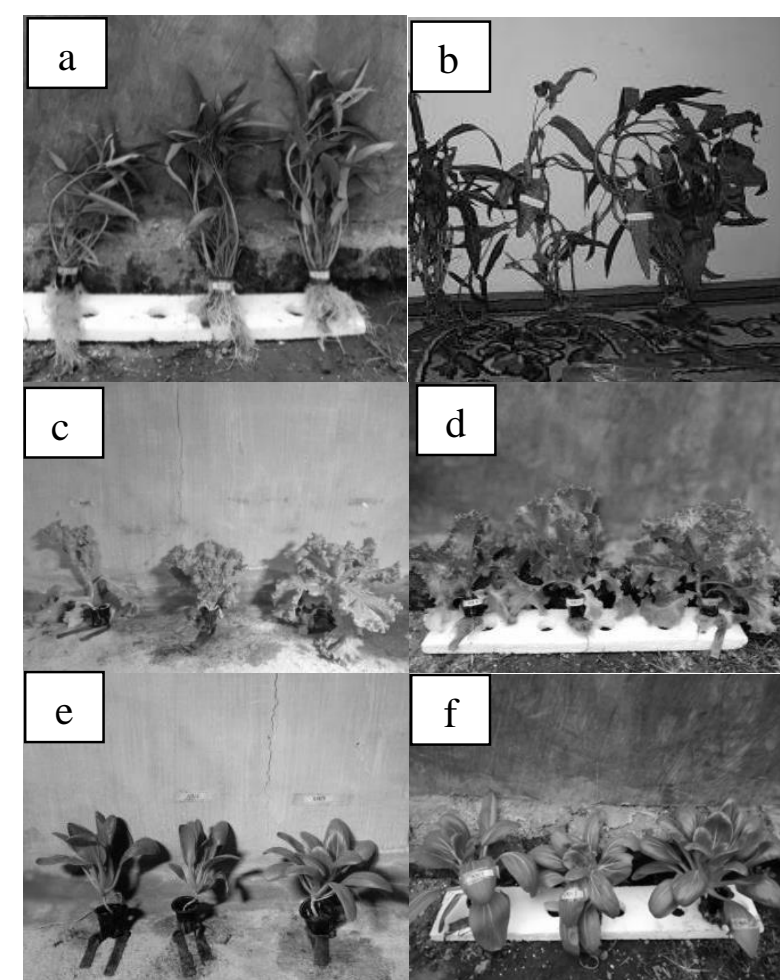

Gambar 2. Hasil tiga jenis sayuran daun pada budidaya akuaponik dan hidroponik (a) kangkung akuaponik; (b) kangkung hidroponik; (c) selada akuaponik; (d) selada hidroponik; (e) pakcoy akuaponik; dan (f) pakcoy hidroponik

Karakteristik fisik tanaman kangkung pada sistem akuaponik menunjukkan hasil lebih tinggi yaitu sebesar $36,27 \mathrm{~cm}$ dibandingkan kangkung hidroponik 30,09 $\mathrm{cm}$. Hal ini sesuai penelitian Nugroho et al. (2012) bahwa perlakuan akuaponik meningkatkan tinggi tanaman sebesar 23$25 \mathrm{~cm}$. Tinggi tanaman selada hidroponik tidak menunjukkan berbeda nyata dibandingkan akuaponik sedangkan pakcoy hidroponik lebih tinggi dibandingkan pakcoy akuaponik yaitu 23,81 $\mathrm{cm}$ (Gambar 3).

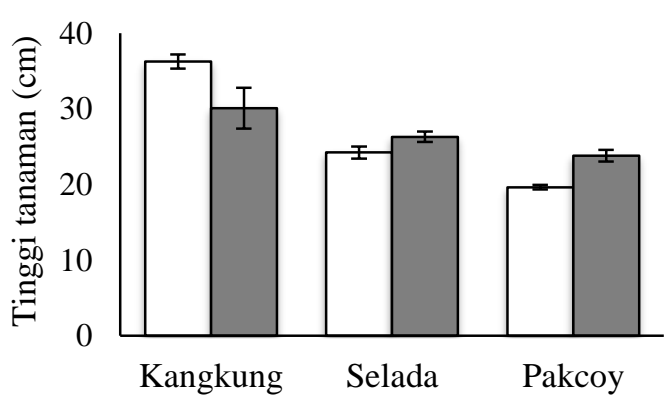

Gambar 3. Tinggi tanaman tiga jenis sayuran dengan sistem akuaponik $(\square)$ dan hidroponik ( $\square$ )

Utami (2015) menyatakan peningkatan tinggi tanaman dapat mendukung penambahan jumlah daun seiring dengan bertambahanya umur tanaman. Hasil penelitian menunjukkan bahwa semakin tinggi tanaman maka jumlah daun lebih banyak. Kangkung akuaponik memiliki jumlah daun lebih banyak yaitu 22,56 helai dibanding kangkung hidroponik 17,44 helai. Jumlah daun selada hidroponik lebih banyak dibandingkan selada akuaponik yaitu 14,11, demikian juga pada pakcoy hidroponik lebih banyak dibandingkan pakcoy akuaponik yaitu 16,11 helai (Gambar 4).

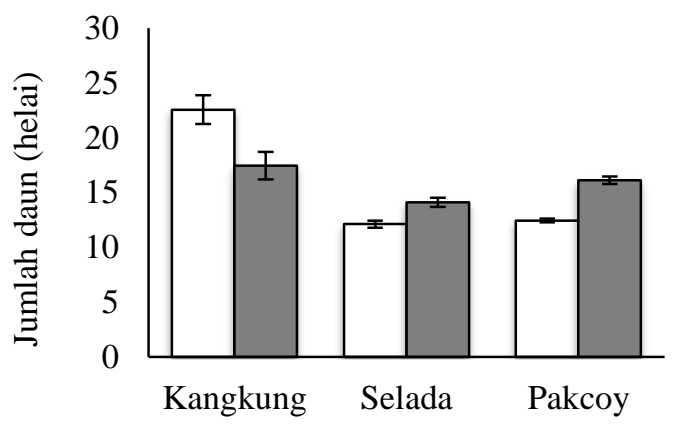

Gambar 4. Tinggi tanaman tiga jenis sayuran dengan sistem akuaponik $(\square)$ dan hidroponik ( $\square$ )

Pada tanaman sayuran daun, lebar daun menjadi indikator visual yang dapat menggambarkan kualitas produksi tanaman. Gambar 5 menunjukkan bahwa lebar daun kangkung akuaponik dan hidroponik tidak menunjukkan berbeda 
nyata. Pada tanaman selada akuaponik menghasilkan lebar daun 15,69 cm. Pakcoy akuaponik dan hidroponik tidak berbeda nyata dengan perolehan hasil tertinggi sebesar $8,06 \mathrm{~cm}$.

Pemberian $100 \% \mathrm{~N}$-limbah cair hasil budidaya ikan lele memberikan hasil lebar daun tanaman sawi tertinggi (Nugroho et al., 2012; Kadarwati, 2006).

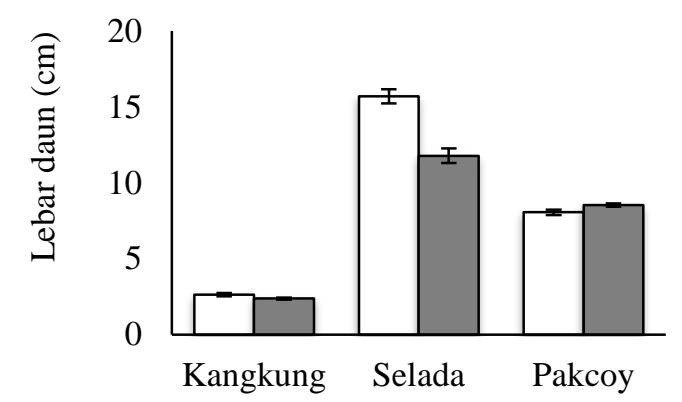

Gambar 5. Lebar daun tiga jenis sayuran dengan sistem akuaponik $(\square)$ dan hidroponik $(\square)$

Secara keseluruhan tanaman sayuran daun baik kangkung, selada atau pakcoy akuaponik menghasilkan daun yang lebih lebar dibandingkan tanaman hidroponik. Hal ini terjadi karena unsur $\mathrm{N}$ tersedia dari limbah kotoran ikan lele dapat meningkatkan hasil fotosintetis dan selanjutnya dapat mempengaruhi pertumbuhan serta perkembangan tanaman. Nilai kandungan hara pada limbah lele ditunjukkan pada Tabel 2.

Tabel 2. Kandungan hara limbah budidaya ikan lele pada penelitian pendahuluan limbah kotoran lele

\begin{tabular}{lcc}
\hline Unsur Hara & Satuan & Limbah cair \\
\hline $\mathrm{pH}$ & Unit & 6,830 \\
C-Organik & $\%$ & 0,169 \\
Nitrogen $(\mathrm{N})$ & $\%$ & 1,680 \\
Phosfor & $\%$ & 2,380 \\
$\left(\mathrm{P}_{2} \mathrm{O}_{5}\right)$ & & \\
$\mathrm{Kalium}$ & $\%$ & 1,390 \\
$\left(\mathrm{~K}_{2} \mathrm{O}_{5}\right)$ & & \\
$\mathrm{C} / \mathrm{N}$ Ratio & $\%$ & 0,100 \\
\hline
\end{tabular}

Berat segar tanaman kangkung menunjukkan hasil terbaik pada perlukan akuaponik (Gambar 6). Meningkatnya tinggi tanaman dan jumlah daun akan berpengaruh pada peningkatan produksi. Hasil penelitian menunjukkan bahwa kangkung lebih tinggi produksinya dibandingkan tanaman hidroponik. Namun pada selada akuaponik dan hidroponik tidak menunjukkan berbeda nyata. Polii (2009), menyatakan bahwa peningkatan jumlah daun tanaman akan meningkatkan berat segar. Berbeda halnya dengan tanaman pakcoy yang menunjukkan hasil lebih baik pada sistem hidroponik dibandingkan akuaponik.

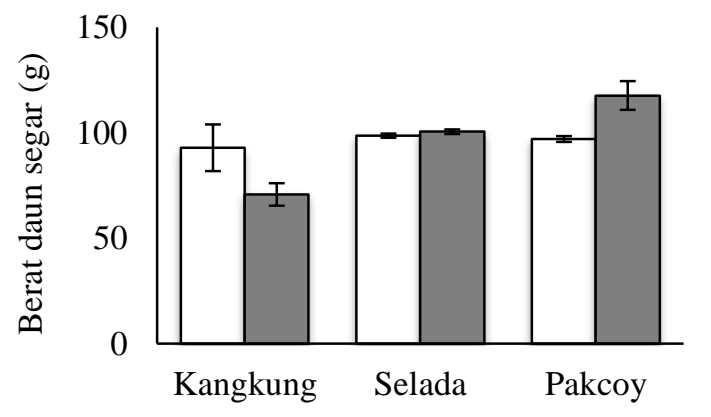

Gambar 6. Berat segar daun tiga jenis sayuran dengan sistem akuaponik $\square$ ) dan hidroponik ( $\square$ )

Dilihat dari volume akar, hasil terbaik tanaman kangkung akuaponik sebesar 49,00 $\mathrm{mL}$ jika dibandingkan dengan hidroponik yaitu 29,44 $\mathrm{mL}$ sedangkan untuk tanaman pakcoy dan selada akuaponik memberikan hasil masingmasing sebesar 23,52 mL dan 22,19 mL, selada dan pakcoy hidroponik terlihat pertumbuhan akarnya lebih baik (Gambar 7).

Biomassa akar sangat dipengaruhi oleh volume akar serta jumlah akar. Semakin banyak jumlah akar maka menyebabkan volume akar dan biomassa meningkat pula. Volume akar pada kangkung akuaponik memiliki hasil terbesar yaitu $49 \mathrm{~mL}$ sehingga penyerapan unsur hara dan air oleh tanaman tersebut tinggi karena pertumbuhan akar dan 
terbentuknya bulu akar baru mempengaruhi terjadi pertemuan antara akar dengan hara pada tanaman. Berdasarkan hasil tersebut, diduga bahwa limbah kotoran ikan mengandung mikroorganisme dan kandungan bahan organik terlarut yang tinggi yang berperan penting dalam menunjang tajuk dan perakaran terutama volume akar (Delaide et al., 2016).

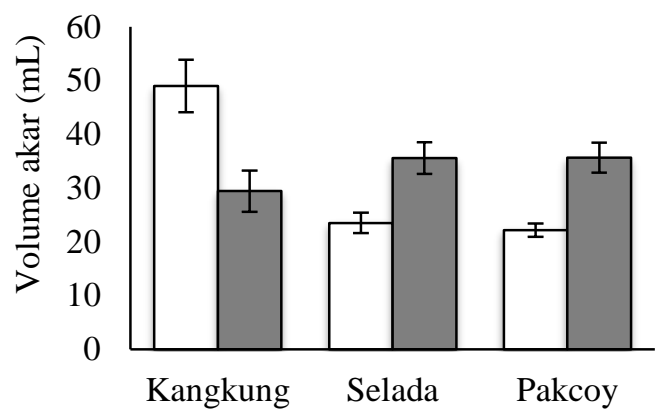

Gambar 7. Volume akar tiga jenis sayuran dengan sistem akuaponik $(\square)$ dan hidroponik (口)

Nilai EC dan TDS menjadi indikator penting dalam untuk sistem budidaya akuaponik maupun hidroponik. Electrical conductivity (EC) menunjukkan jumlah garam terlarut pada nutrisi sedangkan Total Dissolve Solid (TDS) menunjukkan jumlah padatan yang terlarut dalam nutrisi. Pada penelitian ini dilakukan pengukuran EC, $\mathrm{pH}$, suhu udara, dan kelembaban selama penelitian. Tabel 3 menunjukkan bahwa kolam percobaan dalam penelitian masih berada pada nilai batas standar untuk budidaya akuaponik dan hidroponik. Nilai EC merupakan indikator kepekatan nutrisi, semakin tinggi nilai EC maka nutrisi yang diberikan pada tanaman semakin banyak pula. Penelitian Frasetya et al. (2018) menunjukkan bahwa perlakuan EC 1,7 $\mathrm{mS} / \mathrm{cm}$ dan $2,4 \mathrm{mS} / \mathrm{cm}$ dihasilkan berat segar tanaman tertinggi sebesar 79,32 $\mathrm{mS} / \mathrm{cm}$.
Tabel 3. Nilai EC, pH, suhu udara, dan kelembaban selama penelitian

\begin{tabular}{|c|c|c|c|}
\hline \multirow{2}{*}{ Variabel } & \multicolumn{2}{|c|}{ Hasil pengamatan } & \multirow{2}{*}{$\begin{array}{c}\text { Acuan } \\
\text { (Gunawan, } \\
\text { 2016) }\end{array}$} \\
\hline & Akuaponik & Hidroponik & \\
\hline $\begin{array}{l}\text { EC Larutan } \\
(\mathrm{mS} / \mathrm{cm})\end{array}$ & $0,8-1,8$ & $1,2-2,0$ & $1,5-2,5$ \\
\hline TDS (ppm) & $800-1.240$ & $900-1.400$ & $900-1750 *$ \\
\hline pH larutan & $7-7,2$ & $6,5-6,9$ & $5,5-7,5$ \\
\hline $\begin{array}{l}\text { Suhu udara } \\
\left({ }^{\circ} \mathrm{C}\right)\end{array}$ & $27-31$ & $27-31$ & $20-30$ \\
\hline $\begin{array}{l}\text { Kelembaban } \\
\text { udara }(\%)\end{array}$ & $62-84$ & $62-84$ & $70-85$ \\
\hline
\end{tabular}

*Sumber: Farida et al. (2017)

Kandungan klorofil pada masingmasing tanaman sayur juga diamati. Kandungan klorofil daun kangkung, selada, dan pakcoy pada sistem akuaponik sebesar $242,30 \mu \mathrm{mol} / \mathrm{m}^{2}, \quad 96,07 \mu \mathrm{mol} / \mathrm{m}^{2}$, dan 241,15 $\mu \mathrm{mol} / \mathrm{m}^{2}$, sedangkan perlakuan hidroponik dihasilkan nilai $t$ untuk tanaman kangkung, selada, dan pakcoy masingmasing 214,06 $\mu \mathrm{mol} / \mathrm{m}^{2}, 93,71 \mu \mathrm{mol} / \mathrm{m}^{2}$, dan $231,20 \mu \mathrm{mol} / \mathrm{m}^{2}$.

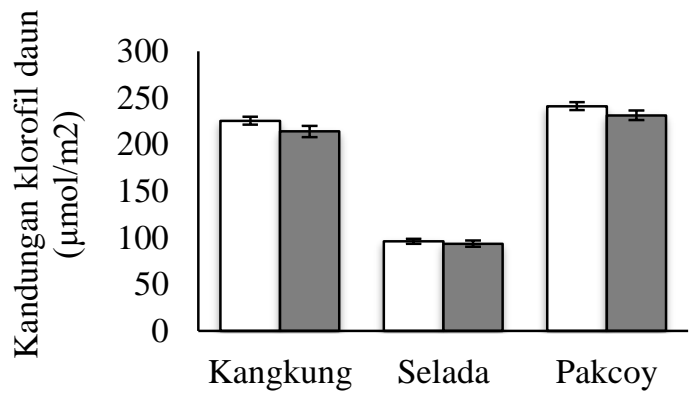

Gambar 8. Kandungan klorofil tiga jenis sayuran dengan sistem akuaponik $(\square)$ dan hidroponik $(\square$ ) 


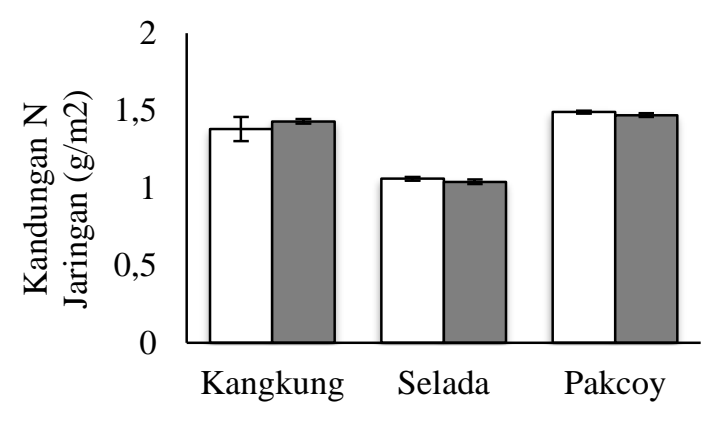

Gambar 9. Kandungan $N$ jaringan pada tiga jenis sayuran dengan sistem akuaponik $(\square)$ dan hidroponik ( $\square$ )

Selain kandungan klorofil, kandungan $\mathrm{N}$ jaringan pada tanaman kangkung, selada dan pakcoy juga diamati (Gambar 9). Hasil analisis kandungan $\mathrm{N}$ jaringan menunjukkan bahwa pada sistem hidroponik, nilai $\mathrm{N}$ jaringan tanaman kangkung sebesar $1,43 \mathrm{~g} / \mathrm{m}^{2}$, sedangkan sistem akuaponik sebesar $1,38 \mathrm{~g} / \mathrm{m}^{2}$. Berbeda dengan selada dan pakcoy yang menujukkan bahwa kandungan $\mathrm{N}$ jaringan pada perlakuan akuaponik yaitu masingmasing $1,06 \mathrm{~g} / \mathrm{m}^{2}$ dan $1,49 \mathrm{~g} / \mathrm{m}^{2}$.

Berdasarkan data hasil analisis pendahuluan limbah kotoran ikan lele (Tabel 2) diperoleh kandungan $\mathrm{N}$ sebesar $1,6 \%$. Hal ini diduga bahwa ketiga jenis sayuran daun ini menyerap unsur hara nitrogen sudah cukup tinggi dari kandungan unsur hara awal yang disediakan.

Peningkatan kandungan $\mathrm{N}$ jaringan dapat berpengaruh terhadap fotosintesis baik lewat kandungan klorofil maupun enzim fotosintetik. Jika kandungan nitrogen daun meningkat, maka fotosintat akan meningkat pul dan jika kandungan nitrogen daun rendah maka fotosintat yang dihasilkan juga akan rendah. Hal demikian disebabkan karena unsur nitrogen akan meningkatkan warna hijau daun, mendorong pertumbuhan batang dan daun (Marschner, 1986). Prasetyo et al. (2018) menyatakan bahwa dengan meningkatnya nitrogen yang diserap oleh tanaman akan berhubungan dengan peningkatan bobot kering, perbaikan perkembangan akar dan peningkatan ketersediaan $\mathrm{N}$ tanah.

Perkembangan ketiga tanaman sayur juga diamati berdasarkan nilai rasio tajuk akar (S/R ratio) (Gambar 10). S/R ratio tanaman kangkung yakni 2,38 g/tanaman jika dibandingkan dengan hidroponik yaitu 1,97 g/tanaman sedangkan perlakuan akuaponik pada selada dan pakcoy ditunjukkan hasil yaitu 1,96 g/tanaman dan 2,45 g/tanaman dibandingkan perlakuan hidroponik 2,29 g/tanaman dan 3,15 g/tanaman. Hal ini menujukkan bahwa pertumbuhan tajuk pada tanaman selada dan pakcoy lebih dominan pada sistem hidroponik jika dibandingkan dengan akuaponik. Sebaliknya, pada tanaman kangkung pertumbuhan tajuk dinilai lebih dominan pada sistem akuaponik jika dibandingkan dengan hidroponik.

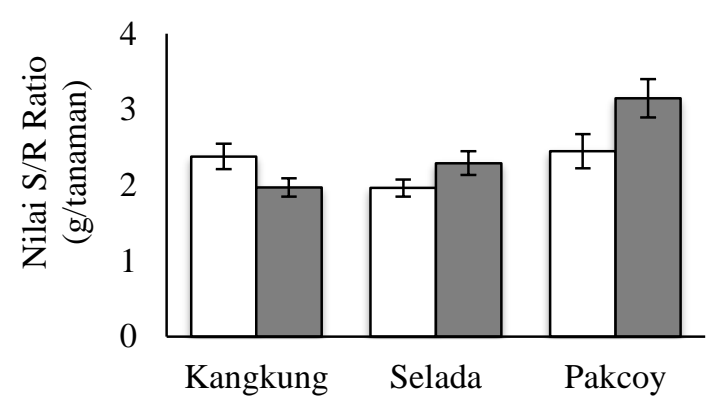

Gambar 10. Shoot/Root ratio tiga jenis sayuran dengan sistem akuaponik $(\square)$ dan hidroponik ( $\square$ )

Nilai S/R ratio dipengaruhi oleh berat kering bagian tajuk:akar. Jika nilai bobot kering tajuk semakin besar maka akan semakin besar pula nilai $S / R$ ratio dan semakin besar nilai berat kering akar maka S/R ratio semakin kecil (Nursanti, 2010). Rasio akar:tajuk menggambarkan proporsi pembagian fotosintat antara bagian tajuk dan akar. Nilai S/R rasio tidak boleh sama dengan satu, jika nilai $S / R$ rasio lebih dari satu maka diasumsikan proporsi fotosintat lebih banyak pada bagian tajuk dari pada bagian akar. Hal demikian dapat diasumsikan bahwa perkembangan tajuk lebih bagus dari pada akar. 


\section{KESIMPULAN}

Pemberian kotoran ikan lele pada sistem aquaponik dapat meningkatkan produksi kangkung sebesar 29,12\% lebih tinggi dibandingkan sistem hidroponik. Berbeda dengan tanaman pakcoy yang justru menunjukkan peningkatan produksi pada sistem budidaya hidroponik sebesar $17,03 \%$ dibandingkan dengan sistem aquaponik. Produksi selada pada sistem aquaponik dan sistem hidroponik menunjukkan nilai berbeda tidak nyata dengan selisih sebesar $1,90 \%$. Hal ini mengindikasikan bahwa tanaman selada dinilai cocok untuk dibudidayakan baik pada sistem aquaponik maupun hidroponik

\section{UCAPAN TERIMA KASIH}

Ucapan terima kasih ini ditujukan LP2M Universitas Jember melalui Hibah Program Pengabdian Kemitraan (PPK) dengan SK Rektor nomer 11329/UN25/PM/2019.

\section{DAFTAR PUSTAKA}

Andreeilee, B.F., Santoso, M., dan Nugroho, A. 2014. Pengaruh jenis kompos kotoran ternak dan waktu penyiangan terhadap produksi tanaman pakcoy (Brassica rapa sub.chienensis) organik. Produksi Tanaman, 2 (3): 190-197.

Andriyeni, A., Firman, F., Nurseha, N., dan Zulkhasyni, Z. 2017. Studi potensi hara makro air limbah budidaya lele sebagai bahan baku pupuk organik. Agroqua, 15 (1): 71-75.

Darwin, H.P. 2012. Pengaruh pupuk organik cair terhadap pertumbuhan dan produksi sayuran daun kangkung, bayam dan caisin. Prosiding Seminar Nasional Perhimpunan Hortikultura Indonesia (Perhorti), pp. 300-306. UPN "Veteran" Jatim, Surabaya, 13-14 November 2012.

Delaide, B., Goddek, S., Gott, J., Soyeurt, H. and Jijakli, M.H. 2016. Lettuce (Lactuca sativa L. var. Sucrine) growth performance in complemented aquaponic solution outperforms hydroponics. Water, 8 (10): 467.
Eckert, D.J. 1987. Soil Test Interpretations: Basic Cation Saturation Ratios and Sufficiency Levels. In: Soil Testing: Sampling, Correlation, Calibration, and Interpretation (Ed) J.R.Brown Madison,WI:SSSA, pp: 53-64.

Effendi, H., Utomo, B.A., Darmawangsa, G. M., dan Karo-Karo, R.E. 2015. Fitoremediasi limbah budidaya ikan lele (Clarias sp.) dengan kangkung (Ipomoea aquatica) dan pakcoy (Brassica rapa chinensis) dalam sistem resirkulasi. Ecolab, 9 (2): 47-104.

Farida, N.F., Abdullah, S.H. dan Priyati, A. 2017. Analisis kualitas air pada sistem pengairan akuaponik. Ilmiah Rekayasa Pertanian dan Biosistem, 5 (2): 385-394.

Frasetya, B., Taofik, A. dan Firdaus, R.K. 2018. Evaluasi variasi nilai electrical conductivity terhadap pertumbuhan tanaman selada (Lactuca sativa $\mathrm{L}$.) pada sistem NFT. Agro, 5 (2): 95-102.

Gardner, F. P., Pearce, R.B., dan Mitchell, R.L. 1991. Fisiologi Tanaman Budidaya. UI press, Jakarta.

Gunawan, S. 2016. 99\% Sukses Budidaya Lele. Penebar Swadaya, Cibubur Jakarta Timur.

Hariati, I., Nisa, T.C., dan Barus, A. 2012. Tanggap pertumbuhan dan produksi bengkuang terhadap beberapa dosis pupuk kalium dan jarak tanam. Agroekoteknologi, 1 (1): 99-108.

Haryadi, D., Yetti, H., dan Yoseva, S. 2015. Pengaruh pemberian beberapa jenis pupuk terhadap pertumbuhan dan produksi tanaman kailan (Brassica alboglabra L.). Jom Faperta, 2 (2): 1-10.

Hendriyani, I.D, dan Setiari, N. 2009. "Kandungan klorofil dan pertumbuhan kacang panjang (Vigna sinensis) pada tingkat penyediaan air yang berbeda". Skripsi. Biologi FMIPA, Universitas Diponegoro, Semarang. 
Indah L. S, Hendrarto, B., dan Soedarsono P. 2014. Kemampuan eceng gondok (Eichhornia sp.), kangkung air (Ipomoea sp.), dan kayu apu (Pistia sp.) dalam menurunkan bahan organik limbah industri tahu (skala laboratorium). Diponegoro Journal of Maquares, 3 (1): 1-6.

Kadarwati, T.F. 2006. Pemupukan rasional dalam upaya peningkatan produktivitas kapas. malang: balai penelitian tanaman tembakau dan serat. Perspektif, 5 (2): 5970 .

Kamalia, S., Dewanti, P., dan Soedradjad, R. 2017. Teknologi hidroponik sistem sumbu pada produksi selada Lollo Rossa (Lactuca Sativa L.) dengan penambahan $\mathrm{CaCl}_{2}$ sebagai nutrisi hidroponik. Agroteknologi, 11 (01): 96-104.

Kementerian Kelautan dan Perikanan. 2018. Refleksi dan Outlook, Jakarta.

Lestari W. 2013. Penggunaan Ipomoea aquatica Forsk. untuk fitoremediasi limbah rumah tangga. Semirata 2013 FMIPA Universitas Lampung. Lampung, Indonesia, 1 (2): 441-446.

Liferdi, L. 2010. Efek pemberian fosfor terhadap pertumbuhan dan status hara pada bibit manggis. Hort, 20 (1): 18-26.

Markwell, J., Osterman, J.C and Mitchell, J.L., 1995. Calibration of the Minolta SPAD502 leaf chlorophyll meter. Photosynthesis research, 46 (3): 467-472.

Marschner, H. 1986. Mineral Nutrition of Higher Plants. Academic Press, London.

Netto, A.T., Campostrini, E., de Oliveira, J.G. and Bressan-Smith, R.E., 2005. Photosynthetic pigments, nitrogen, chlorophyll a fluorescence and SPAD502 readings in coffee leaves. Scientia Horticulturae, 104 (2): 199-209.

Nugroho, R.A., Pambudi, L.T., Chilmawati, D. dan Haditomo, A.H.C. 2012. Aplikasi teknologi aquaponic pada budidaya ikan air tawar untuk optimalisasi kapasitas produksi. Saintek Perikanan, 8 (1): 4651.
Nursanti, I. 2010. Tanggap pertumbuhan bibit kelapa sawit (Elaeis guineensis Jacq.) terhadap aplikasi pupuk organik berbeda dosis. Jurnal Ilmiah Universitas Batang Hari Jambi, 1 (1): 13-17.

Oktabriana, G. 2017. Upaya dalam meningkatan pertumbuhan tanaman sawi hijau (Brassica juncea L.) dengan pemberian pupuk organik cair. Agrifo: Jurnal Agribisnis Universitas Malikussaleh, 2 (1): 12-19.

Petrea, S.M., Cristea, V., Dediu, L., Contoman, M., Stroe, M.D., Antache, A., Coadă, M. T., and Placinta, S. 2014. Vegetable production in an integrated aquaponic system with stellate sturgeon and spinach-matador variety. Animal Science and Biotechnologies, 24 (1): 235-245.

Polii, M.G.M .2009. Respon produksi tanaman kangkung terhadap variasi waktu pemberian pupuk kotoran ayam. Soil Environment, 1 (7): 18-22.

Prasetyo, H.P., Pata'dungan, Y.S., dan Isrun. 2018. Pengaruh pupuk kandang domba terhadap serapan nitrogen $(\mathrm{N})$ tanaman selada (Lactuca sativa L.) pada entisols lembah palu. Agrotekbis, 6 (4): 506-514.

Putra, I., Mulyadi., Pamukas, N.A., dan Rusliadi. 2013. peningkatan kapasitas produksi akuakultur pada pemeliharaan ikan selais (Ompok sp) sistem aquaponik. Perikanan dan Kelatuan, 18 (1): 1-10.

Rokhmah, N.A., Ammatillah, C.S., dan Sastro, Y. 2014. Vertiminaponik, mini akuaponik untuk lahan sempit di perkotaan. Buletin Pertanian Perkotaan, 4 (2): 14-22.

Ruhnayat, A. 2007. Penentuan kebutuhan pokok unsur hara $\mathrm{N}, \mathrm{P}, \mathrm{K}$ untuk pertumbuhan tanaman panili (Vanilla planifolia Andrews). Buletin Littro (http://balittro.litbang.deptan.go.id/ind/i mages/stories/Buletin/.../5-panili.pdf,) [Diakses tanggal 14 Agustus 2011]. 
Saptarini, P. 2010. "Efektivitas Teknologi Aquaponik Dengan Kangkung Darat (Ipomoea reptans) Terhadap Penurunan Amonia pada Pembesaran Ikan Mas". Skripsi. Departemen MSP FPIK, Institut Pertaian Bogor, Bogor.

Sari, B.P., Santoso, M., dan Koesriharti. 2016. Pengaruh komposisi media tanam dan pupuk nitrogen terhadap pertumbuhan serta hasil tanaman sawi pak choi (Brassica rapa L var. Chinensis). Produksi Tanaman, 4 (5): 399-405.

Setiawan, H. 2017. Kiat Sukses Budidaya Cabai Hidroponik. Bio Genesis, Yogyakarta.

Setijaningsih, L., dan Umar, C. 2015. Pengaruh lama retensi air terhadap pertumbuhan ikan nila (Oreochromis niloticus) pada budidaya sistem akuaponik dengan tanaman kangkung. Berita Biologi, 14(3): 267-275.

Syariefa, E., Duryatmo,S., Angkasa, S., Apriyanti, R.N., Raharjo, A.A., Rizkika, K., Rahimah, D.S., Titisari, A., Setiyawan, B., Vebriansyah, R., Fadhila, R., Nugroho, H., dan Awaluddin, M. 2014. Hidroponik Praktis. PT. Trubus Swadaya, Jakarta.

Tintondp. 2015. Hidroponik Wick System. PT Agro Media Pustaka, Jakarta.

Utami, S. 2005. "Pengaruh Sistem Olah Tanah Terhadap Pertumbuhan dan Hasil Jagung Manis (Zea mays Saccharata Strurt)". Skripsi. Fakultas Pertanian Universitas Muhammadiyah Yogyakarta, Yogyakarta.

Widuri, L.I., Lakitan, B., Hasmeda, M., Sodikin, E., Wijaya, A., Meihana, M., Kartika, K., and Siaga, E. 2017. Relative leaf expansion rate and other leaf-related indicators for detection of drought stress in chili pepper (Capsicum annuum L.). Australian journal of crop science, 11 (12): 1617-1625. 